\title{
The Inevitable Future of Generic Pharma Drugs Companies
}

\section{Eran Eilat*}

Founder of few Drug Delivery Companies, Israel

\begin{abstract}
Fierce competition and public pressure on pharmaceutical companies pose challenges for ethical and generic pharma companies. 7-10\% annual price erosion for generic companies leads to decreased profitability. Increased competition combined with pressure from payers, push margins lower. Competition made its mark on of some global generic players and led to the rise of Indian companies, however price erosion also affects these players. The ability of the generic companies to increase their margins are key elements in their survivor and thrive. The way to achieve that is by utilizing drug delivery technologies that can introduce added-value within limited investments (as low as US\$ 10-20M), through the 505(b)2 regulatory process (a similar process has been adopted by the European agency and recently by the Chinese authority). Herein I will share my views on this inevitable future of generic pharmaceutical companies.
\end{abstract}

\section{Keywords: Generic drug; Regulatory agency; Drug delivery}

During the last decades constant public pressure and competitive landscape lead the generic pharma industry to experience a turbulent environment. Due to increased healthcare costs governments and insurance companies have supported the change to generic replacements. The Waxman-Hatch Act of 1984 in the US was a strong driver for companies to enter the generic field and increase profitability. While ethical drug is protected by patents and hence creates a timelimited monopoly, thus gaining an "unfair advantage" that allows the owner to receive a high-end profit (some would claim even greedy profits, though ethical companies do not pose outstanding profit rates), there is an expiry date, the day when patent protection ends. When an ethical drug becomes a generic it is destined to become a commodity. In a global and highly competitive markets "commodity" means costs + margin, this margin is the driving force of the generic industry.

The economic burden of ethical drug development is reflected by the increased costs of drug development which is steadily increasing. Figure 1 shows that in the late 1990s new drug developmental costs were \$0.9B [1] doubled within few years into $\$ 1.8 \mathrm{~B}$ in 2003 with almost $50 \%$ increase into $\$ 2.6 \mathrm{~B}$ in 2018 [2] with only one in ten thousand compounds makes it to the market [3]. These have put financial pressure on the ethical companies to increase drug prices, which led to a pressure on politician to reduce this burden [4]. This led the ethical companies to struggle keeping profitability on approved drugs for extended periods. There are few preventive strategies used by ethical companies:

1. Pre-emptive Launch: Launching a generic formulation before patent expiration to lengthen the period of attractive profitability by using "approved generic" policy.

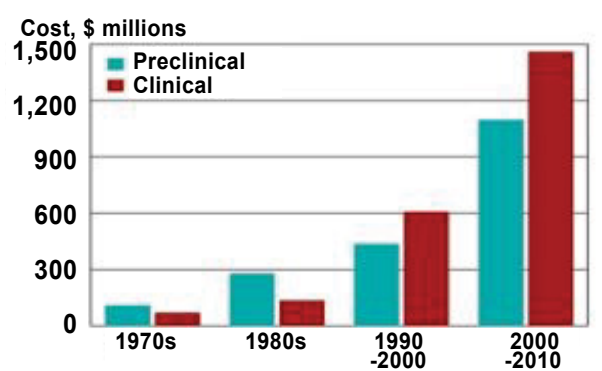

Figure 1: The changes in cost of developing a new drug since the 1970s. Source: Tufts center for the study of drug development.
2. Regulatory extension: Extending exclusivity by adding FDAprotected periods by conducting additional clinical trials (e.g. paediatric population).

3. Innovative extension: Altering a chemical composition to create patentable version of a product with an expiring patent (reformulation, Rx-to-OTC switch, new indications etc [5].

4. Legally fighting generic competition: Filing a patent infringement suit to fight generic drug launch [6]

The ethical companies end of exclusivity period "feeds" the generic pipeline, this enables reducing the drug's price and hence makeing it more affordable. The entrance of generic competition typically results in prices about $85 \%$ less than the original ethical brand-name. According to the IMS Health Institute, generic drugs saved the U.S health care system \$1.67 trillion from 2007 to 2016 [7]. However, generic drug prices decline with time, in recent years the decline rate became significantly faster [8]. The generic annual price erosion is estimated at $7-10 \%[8,9]$. This led to the profit margins of the generic industry to shrunk. Taking into consideration that the fixed costs (API, labor, machinery and operation) did not change at the same pace, most of the price reduction is being translated directly into the bottom line of profits, which led to a race toward "costs reduction", the generic company that can sell the drug in a lower price (along with accepted regulatory quality assurance requirements) will be able to compete (Figure 2). Technology improvements allowed some price reduction, but this have limitations, and labor costs pushed production into some low-labor-costs countries, such as India. The Indian generic industry took the challenge, met the FDA regulatory requirements and gained position in the main pharmaceutical market, namely the USA. Production is being transferred to India, enabling compering this market and beyond. Many generic companies have open subsidiaries in India, alongside with the raise of Indian generic

*Corresponding author: Eran Eilat M.D., Ph.D., Entrepreneur, Drug Delivery Companies, Israel, Tel: +972-544-562972; E-mail: eran@peritech-p.com

Received May 22, 2018; Accepted May 31, 2018; Published June 11, 2018

Citation: Eilat E (2018) The Inevitable Future of Generic Pharma Drugs Companies. J Bioequiv Availab 10: 48-49. 376. doi: 10.4172/0975-0851.1000377

Copyright: (c) 2018 Eilat E. This is an open-access article distributed under the terms of the Creative Commons Attribution License, which permits unrestricted use, distribution, and reproduction in any medium, provided the original author and source are credited. 


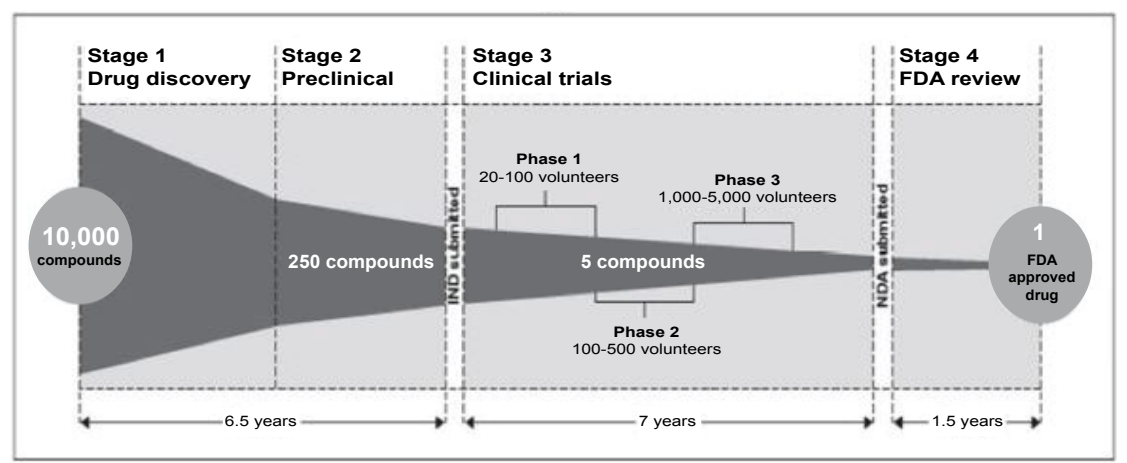

Figure 2: The roadmap of developing a new drug from the bench to the regulatory approval. Source: Pharmaceutical Research and Manufacturers of America.

companies. A steep decline in the profit after tax and margins intensity of the pharmaceutical firms can be observed post-2011 with some signs of recovery after 2013. Increased competition and the Indian government aggressive price pressures has resulted in profits erosion from $20 \%$ to $16 \%$ (and $10 \%$ to $8 \%$ for retailers and distributors) [10]. By looking at the Indian generic pharma companies it is quite clear that the generic pharmaceutical market is aimed to a price crisis, that is driven by steady price decline with the fixed costs. Currently, many leading generic companies are already facing this crisis, and confront it by cutting expensed and significant lay-offs. In my view looking into the near future this is not sustainable, fully automated drug production are on their way. Such automated production shall reduce labor costs to almost nothing. This scenario, in my view, is inevitable. So, what can be done?

Healthcare consumers are willing to pay for better treatment. What better means? It means: more efficacious, safer with less side effects, more convenient, etc. Drug delivery also called super-generics, addedvalue-generics, etc., basically these are generic drugs that are improved by modification. Improvement can be by increasing effectiveness, reducing side effects or improving compliance, thus can be achieved by changing the inactive ingredients, combining active drugs, adding a medical device etc. These changes which do not affect the active product ingredient (API) fall under a unique regulatory pathway. Regulatory agencies like the FDA (and others as well) have a designated regulatory pathway for these changes, namely 505(b)2, also called "repurposing" or "repositioning". Such application in which one or more of the investigations relied upon by the applicant for approval "were not conducted by or for the applicant and for which the applicant has not obtained a right of reference or use from the person by or for whom the investigations were conducted" [11]. Basically, it says, the regulatory agency approved the API and knows it is safe and effective, therefore applicant needs to prove that the changes made as as-good-as the approved drug. Changes that fall under this section include:

1. Dosage form: An application for a change of dosage form, such as a change from a solid oral dosage form to a transdermal patch, that relies to some extent upon the Agency's finding of safety and/or effectiveness for an approved drug.

2. Strength: An application for a change to a lower or higher strength.

3. Route of administration: An application for a change in the route of administration, such as a change from an intravenous to intrathecal route.

4. Substitution of an active ingredient in a combination product: An application for a change in one of the active ingredients of an approved combination product for another active ingredient that has or has not been previously approved.

This regulatory pathway requires much shorter duration to reach the market (2-5 years as opposed to 8-15 years with new drug development) [12], and costs are significantly reduced, a full 505(b) 2 product can be fully developed and approved for US\$10$20 \mathrm{M}$. On the other hand, with patent protection the drug delivery product receives exclusivity period (some exclusivity of up to 7 years with the 505(b)2 approval and some by the patent protection). Since products under protection (regulatory exclusivity or patent protection) pose a higher price tag, such approach allows to widen margins on the same API significantly and gives competitive advantage in the industry, this is the inevitable future.

\section{References}

1. Moran M (2003) Cost of bringing new drugs to market rising rapidly. Psychiatric News 38: 25.

2. http://www.bio-itworld.com/2018/01/02/using-patent-data-for-drugdevelopment.aspx

3. http://www.keepcalmtalklaw.co.uk/case-study-patents-help-or-hindrance/

4. https://www.cnbc.com/2018/05/11/president-trump-unveils-prescription-drugprice-plan.html

5. Pearce JA (2006) How companies can preserve market dominance after patents expire. Long Range Plan 39: 71-87.

6. Song CH, Han JW (2016) Patent cliff and strategic switch: exploring strategic design possibilities in the pharmaceutical industry. SpringerPlus 5: 692.

7. http://www.imshealth.com/en/thought-leadership/quintilesims-institute/reports

8. https://www.ftc.gov/system/files/documents/public_events/1255653/ understanding_competition_in_prescription_drug_markets_workshop_ slides_11-8-17.pdf

9. Tyagi S, Nauriyal D (2016) Determinants of Profitability in Indian Pharmaceutica Firms in the New Intellectual Property Rights Regime. Inter J Social, Behavioral Educational, Economic, Business and Industrial Engineering 10: 2401-2408.

10. https://www.pwc.in/assets/pdfs/publications/2013/changing-landscape-of-theindian-pharma-industry.pdf

11. https://www.fda.gov/downloads/Drugs/Guidances/ucm079345.pdf

12. https://camargopharma.com/what-is-505b2/ 